\title{
THE JAM SESSION MODEL FOR GROUP CREATIVITY AND INNOVATIVE TECHNOLOGY
}

\author{
Maksim Belitski \\ Henley Business School, Whiteknights, University of Reading, Reading, RG6 \\ 6UD, \\ United Kingdom \\ m.belitski@reading.ac.uk \\ Monika Herzig \\ Arts Administration, School of Public and Environmental Affairs, Indiana \\ University, Bloomington, Indiana, 47405, United States \\ mherzig@indiana.edu
}




\begin{abstract}
This paper builds on the analysis of factors observed at jazz jam sessions facilitating team creativity and improvisation as a model for managing organizational innovation. The model was established through detailed observations, surveys, historical research, and interviews. Even though the jazz metaphor has been used as a model for organizational improvisation the discussions rarely extend beyond the improvisational process of idea generation (Frishammar, Dahlskog, Krumlinde and Yazgan, 2016) towards a comprehensive model for team creativity and effective organizational management (Santos, Uitdewilligen and Passos, 2015). The seven factor Jam Session Model for Group Creativity and Innovative technology is built from a comprehensive analysis of the jam session process and exemplified with case studies of leading innovative companies such offering a theoretical and practical model for managing and facilitating group creativity and innovative technology.
\end{abstract}

Keywords: Organizational Improvisation, Creativity, Jam session, Group Creativity, Innovative technology

\title{
INTRODUCTION
}

Although a team's creativity and cognitive architecture are acknowledged as key components of organizational improvisation (Moorman and Miner, 1998) and performance (Hargadon and Bechky, 2006; Perry-Smith and Shalley, 2014; Frishammar, Dahlskog, Krumlinde and Yazgan, 2016), there has been a disparity in the conceptualization of creativity and the role that improvisation in a group setting can play for ideas and new knowledge creation (Zack, 2000). Creativity is defined as "the mental and social process - fueled by conscious or unconscious insight of people - of generating ideas, concepts and associations” (Serrat, 2010). Thus it is central to sustained organizational performance, used in conjunction with innovation, the "successful exploitation of new ideas" (Serrat, 2010) and a wide range of improvisational behaviors (Zack, 2000; Hadida et al., 2015) to firms who skillfully manage and nurture team creativity.

While recent theoretical and empirical innovation management literature offers a variety of important factors that facilitate innovative technology through the creation of new knowledge (Tsoukas, 2009), the findings are not consistent. It was suggested to search for alternative models of team creativity and organizational improvisation outside the business economics and management literature. For example, Vera and Crossan (2005) exemplified the use of improvisational theater principles such as "practice," "collaboration," "agree, accept, and add," "be present in the moment," and "draw on reincorporation and ready-mades" as tools to improvise well in teams and to create an environment favorable to improvisation. Holbrook (2008) and Zack (2000) highlighted that creativity and innovation lie at the heart of most musical performances - particularly in the jazz genre known as the jazz metaphor for entrepreneurship. Lewin (1998) and most recently Holbrook (2008), for example, propose an expanded view of the jazz metaphor as a broadened perspective that embraces a wide range of possibilities in organizational, management, and marketing-related themes. Recent research in creativity and innovation management literature expanded our understanding on the role that team creativity plays in innovation and effectiveness of organizations (Santos, Uitdewilligen and Passos, 2015). Frishammar, Dahlskog, Krumlinde and Yazgan (2016) provided numerous theoretical 
implications and debated how firms can increase their degree of novelty and success with new ideas and concepts. Building on the front end innovation (FEI) theory, Aagaard and Gertsen (2011) explored how radical front end innovation is supported using explorative case study of front end innovation in the pharmaceutical industry.

This study builds on the original seven factor model developed by Herzig and Baker (2014) through literature reviews, surveys and in-depth interviews with jazz musicians. These factors include: Individual competency and knowledge of the field, practicing improvisation, establishing mentoring systems and role models, democracy and collaboration, leaders and sidemen, community support, and continuous evaluation systems. Taken together these factors were found essential for the process of collaborative creativity and innovation (Audretsch, Hayter, and Link, 2015). Multiple case studies of innovative technology firms provide an empirical test for the jam session model and explain how innovation could be achieved. The seven factor model and related research clearly demonstrate that the process of group innovation can be managed effectively using the model as an analysis and implementation tool. Overall, heightened levels of entrepreneurial activity have been proven to be related to education and strong entrepreneurial ecosystems (Cohen, 2005; Klapper, et al., 2007; Wessner, 2005). Although organizational innovation and the jam session model are functionally different, we argue that they share the same representational space metaphorically and methodologically (Meyer et al., 1998), as for instance, organizational routines (Dittrich et al., 2016) and creative projects (Obstfeld, 2012).

Building the jam session model (Herzig and Baker, 2014) and exemplifying the factors with multiple case studies from the world's most innovative companies (Forbes, 2015), this study enables the transfer of the jam session model to a variety of business and technology applications. We propose that the jam session model facilitates group creativity and organizational innovation and can be applied to facilitate creative group interaction in any field as an analysis and training tool. Our findings demonstrate that the impact of each factor is heterogeneous and idiosyncratic with a number of factors overlapping at times and complementing each other, bringing together the puzzle of group creativity and innovative technology.

\section{DeVelopment of The JAM SESSion Model For Group Creativity AND InNOVATIVE TECHNOLOGY}

The model was first proposed by Herzig and Baker (2014) within a project that documented the creative process of the jazz jam session from a historical, social, and musical perspective, and offered applications for group creativity. While there are scholars who have researched the creative process of jazz musicians and general creative thinking techniques (Cameron, 1956; Weick, 1990; Barrett, 1998; Meyer et al., 1998; Moorman and Miner, 1998; Hatch, 1998; Becker, 2000; Dennis and Macaulay, 2003; Sawyer, 1992, 2006; Holbrook, 2008), Herzig and Baker (2014) used an in-depth historical and social perspective based on personal interviews, surveys, and a variety of historical documents to build a comprehensive model. The analysis of the jam session process revealed seven factors that facilitate group creativity and innovation. Definitions and examples of these factors frame a model for innovative group interaction, thus serving the needs of developing new ideas and technology in teams (Bastien and Hostager, 1988). 


\section{History and Process}

Originally used as a verb, jamming indicated cramming as many musicians as possible into one room. Carr et al. (1987) suspect though that the idea of cramming the maximum number of ideas into each improvised solo comes closer. The term jam session came to denote informal gatherings of musicians allowing for extended playing opportunities away from the demands of their regular jobs. The sessions also provide learning and mentoring opportunities for artists of diverse playing levels and career stages (Kao, 1996).

A set of shared expectations and goals have shaped rules and norms for jam sessions that maintain a social structure and provide the basis for successful interaction. These rules are highly flexible and open for revision depending on the circumstances of any particular jam session, but overall help maintain a degree of stability (Nelson, 1995), enable creative collaboration and reduce individual uncertainty (Bastien and Hostager, 1988, p. 586). Musicians who are familiar with the song may use this information in creating variations on musical themes. Hence, the level of collaborative creativity then directly depends on the skill and knowledge level of all collaborating musicians, with the weakest participant dictating the limits of creative potential. Social structures include behavioral norms and communication etiquette usually in the form of visual and verbal cues.

Several social mechanisms and communication tools are typically present to maintain basic etiquette rules. Nelson (1995) identifies three such social mechanisms that help mediate the tension between the need for personal creativity versus the need for cooperation among the participants. First, a designated leader helps facilitate performers and their order of appearances, tunes, and tempos with varying degrees of control. Nelson refers to the second mechanism as 'sanctioning behavior,' consisting of facial expressions, body language, comments or a change in performance level and expression. Other tools include a standard terminology known by the jazz insiders, such as the 'head' referring to the main melody of the tune, or trading fours to a practice of exchanging bars of four between the soloists and the drummer, or 'rhythm changes' as a particular kind of form and harmonic structure. Most musicians have to pay their dues, meaning they have to prove themselves and show their commitment before being accepted in the jazz community (Berliner, 1994). The social structure of jam sessions can be described as concentric circles around a core of performing musicians clustering together on stage, with the second tier being the musicians waiting to get their turn and the third tier any audience members attempting to look into that inner circle without disturbing the ambience (DeVeaux, 1997).

\section{Methodology}

In order to identify the factors and analyze the jam session model, Herzig and Baker (2014) collected data based on literature reviews, personal interviews, video analysis, and survey data. A preliminary survey conducted in 2009 with 178 participants indicated that most jazz musicians are initially attracted to the art form through recordings, live performances, and role models because of its unique process of improvisation and self-expression. All respondents rated frequent participation in jam sessions as essential and indicated that the social aspect, acquisition of repertoire and improvisational skills were the most important learning outcomes. Feedback on positive and negative experiences as well as organizational details grouped into the seven factors outlined below. 
A second survey was administered during April - November 2012 with 370 respondents ranging from beginners to pros and a wide variety of ages and instruments. The answers provided additional information on the relationship of age and participation, essential repertoire, different environmental factors, and dynamics among participants. Beyond the benefits indicated in the initial survey, mentorship and networking ranked very high. The need for a supportive community and positive attitude were also mentioned frequently. Inhibiting factors for the musical process were lack of technical ability, lack of repertoire, and not abiding to the democratic principles of a jazz combo.

The research team initiated a series of interviews with 10 faculty members and students at the 2013 Jamey Aebersold Summer Jazz Workshop. Interviewees commented on the historic significance, common jam session practices, their own participation habits, common repertoire, and etiquette observations. In addition, we extracted any information and anecdotes on jam sessions from the complete repository of the Smithsonian Oral Jazz History collection of nearly 120 interviews with distinguished jazz artists. The anecdotal data exemplified and elaborated on the comments and suggestions from the survey. Finally, an extensive literature review and video analysis from two recent jam sessions guided the identification of the following seven factors that guide the musical interaction and influence the quality of the results.

\section{The Seven Factors of the Jam Session Model}

\section{Individual competence and knowledge of the field}

Limited competence and knowledge of one participant inhibit the creative potential of the whole group. Jazz musicians spend hours every day listening to, imitating, and transcribing jazz icons (Berliner, 1994). Vera and Crossan (2005) have emphasized the enormous role that individual competence plays in the development of improvisational skills. The leading reason for negative experiences at jam sessions in both surveys was limited abilities and unpreparedness of fellow players while the leading reason for positive experiences was the leadership of outstanding musicians.

\section{Practicing improvisation as the ability to overcome self-consciousness}

As Vera and Crossan (2005) state, "improvisation is not inherently good or bad; however, improvisation has a positive effect on team innovation when combined with team and contextual moderating factors”. Similar to improvisational theatre, participation in a jam session requires taking a series of risks such as entering an unknown group of musicians, using instruments or amps that belong to someone else, possibly playing unfamiliar repertoire, and engaging in improvisation in front of an unfamiliar audience. According to research by Limb and Braun (2008), jazz musicians actually train their brains in this type of risk-taking by extensive deactivation of the prefrontal cortex as they engage in the process of improvisation. Although improvisation may be constrained within certain rules (Hatch, 1998; Vera and Crossan, (2005), breaking the rules of the genre is known as playing "outside," as in "outside the norm" or "outside the accepted musical structure” (Zack, 2000). Peplowski (1998, p. 560) adds "We are always deliberately painting ourselves into corners just in order to get out of them. Sometimes you consciously pick a bad note and try to find a way to get out of it. The essence of jazz music is to try to put three to eight people together while they're all trying to do this at the same time”.

\section{Establishing a mentoring system and role models}


The mentoring aspect of jam sessions historically developed from a need to learn the art form through oral imitation with no written materials available. More established players instructed younger players on the bandstand and functioned as role models. Further evidence is a study on artistic creativity and interpersonal relationships conducted by Dean Keith Simonton (1984) that documented the positive correlation of a large number of diverse models and mentors to a successful artist career. Participation in jam sessions in order to learn from experienced players is still valued very highly as evidenced by a 4.56 rating on a 5-point likert scale for the 2012 survey.

\section{Democracy and collaboration}

The collective product rises and falls with the willingness of each performer to engage in this truly democratic process of trading leadership and supporting roles and contributing towards the common good at every moment during a performance. The crucial element is the ability and willingness of participants to exchange roles in the group and provide equal opportunity for everyone to step forward as a soloist while all other musicians assume supporting roles.

This is an important factor to address criticism of racism in the organizational discussions surrounding the jazz metaphor (Meyer et al., 1998; Holbrook, 2008) referring to the fact that "jazz was originally developed by blacks in the southern U.S. as a countercultural form of expression by an oppressed minority” (Hatch and Weick 1998, p. 601) and has been appropriated by groups all over the world. The factor of democracy and collaboration is evident when group members listen to each other (Hatch and Weick, 1998) in open discussions and trade off leadership independently of team member's backgrounds.

\section{Leaders and side(wo)men}

An experienced performer often takes on a leadership role in a jam session functioning as liaison between the venue management, the house band, the jam session participants and the audience. For a variety of reasons, musicians might not be willing to take on such managerial tasks and rather be what is commonly referred to as 'sidemen.' As such they need to develop musical versatility in order to meet the demands of any musical settings they might get hired for. Barrett refers to this factor as provocative competence (Barrett 2012, p. 139). The importance of identifying a leader for the sessions was rated at 3.5 on a 5-point likert scale and many anecdotes from the interviews and oral history transcripts referred to various leadership styles and their influence on session dynamics. The implication is that participants need to identify their ideal role in such a group setting in order to function effectively. Of course, roles may change when entering a different groups with different dynamics.

\section{Community support}

Despite low economic prospects with musicians often moonlighting and working second jobs, jazz musicians display a high degree of intrinsic drive and the jam session becomes a community of learning through social interaction and support. The segregated black community clustered around Indiana Avenue in Indianapolis during the 1930s and 1940s was small but extremely supportive and full of opportunities. Indiana Avenue was lined with more than 40 clubs hosting nightly jam sessions and the teachers at Crispus Attucks High School believed in and supported the creativity and potential of their students. A host of legendary jazz musicians including Wes Montgomery, Slide Hampton, Freddie Hubbard, J.J. Johnson, David Baker, Larry Ridley and many more were the result of this community investment (Herzig, 2011). 


\section{Continuous evaluation systems}

Immediate feedback shapes the jam session process with facial expressions, body language, comments, cues and common vocabulary, and response to audience feedback. Similarly, recent research on brainstorming techniques confirms that groups who also engage in active debate and critical feedback on ideas beyond traditional brainstorming are able to generate more meaningful results (Feinberg and Nemeth, 2008).

Proposition: The jam session model originally developed by Herzig and Baker (2014) facilitates group creativity and innovative technology. The model can be effectively applied to creative group interaction in any field as an analysis and training tool for group innovation.

\section{MODEL ANALYSIS}

Defining jam sessions as "flexible, adaptable, responsive to the environment, loose boundaries, minimal hierarchy" (Hatch, 1998, p. 557) the jam session model offers new ways of organizing creative community interaction and reveals rich connections to the business community. This section exemplifies the application of the jam session model for creative communities and entrepreneurial units. Thus we demonstrate how the model is used, whether consciously or not, in a corporate environment to facilitate creativity and innovation in organizations independent of their background and industry, technology they use, age and size. Initially the link between the jam session model and organizational innovation may seem abstract, but as we exemplify each factor with a case study based on the Forbes list of most innovative companies (Dyer, J., \& Gregersen, H., 2015), the connection becomes clear and intriguing.

\section{Individual Competence and Knowledge of the Field}

The quality of the musical product during a jam session is highly dependent on participants' individual competence and knowledge of the field, as the first secret of organizational innovation. This relates to the organization's ability to possess a skilled and knowledgeable workforce, whilst also having them impart knowledge to other employees. In order to achieve a high competency and knowledge level within the firm and promote experimentation and innovation it is crucial to find people that fit into a high performance-high knowledge culture. In an interview with Richard Plepler, the CEO of HBO, he explained "The blessing for us is that there is an unbelievable array of talent, lined up at the door that want to work at HBO" to follow that "potential for innovation becomes possible as only the most talented are employed to work" (Buzzfeed, 2015).

At Sony, selection criteria are 'well-versed in the hardware businesses and having 'diverse career backgrounds and experience in other business categories'. This would allow experienced business leaders to enter management roles and be 'autonomous managed' (Hirai, 2015)-.

Another example for improving competency and knowledge can be observed at Tesla Motors. The fact, that CEO Elon Musk convinced his CIO to join and build the software needed to run the company in three months for a fifth of the price was initially seen as an impossible 
task requiring supreme individual competency of the CIO, but also a culture of challenge and learning while working at Tesla Motors (Dyer et al., 2015).

Amazon's philosophy is to "Hire and Develop the Best" (Blodget, 2014) and is a company that will keep on looking until they find the right talent (Cook 2014). Amazon offers a career choice program that provides 95\% of tuition towards educational courses for employees not necessarily relevant to Amazon's business model (Cook, 2014). This demonstrates a significant investment in fostering highest levels of knowledge and people’s competencies.

\section{Practicing Improvisation as the Ability to Overcome Self-consciousness}

Participating in a jam session includes a large amount of risk as it involves performing on a stage with new musicians, new instruments and to a different audience almost every time. Jazz musicians practice improvisation on a regular basis as it is a key element of the art form but also fosters their willingness to take risks. Similarly, improvisational skills facilitate adjusting to change and finding new solutions to organizational routines (Obstfeld, 2012; Dittrich et al., 2016) including new products and services. An example for such organizational improvisation is the introduction of PlayStation by Sony, a gaming service that allows for old games to be played on new consoles in response to Microsoft's announcement that the Xbox One would provide backwards compatibility with previous Xbox games. Despite the difficulties caused by the compatibility needs, Sony reacted quickly to an eminent market need. Recently, Sony displayed improvisational capacities on a much larger scale with immediate adaptions in management structure after the Sony Pictures hack (Derousseau, 2015). Especially when introducing a new product to the market, using improvisational tactics may be costly and technologically challenging (Nokia, 2015) but nevertheless the key to success when adapting quickly to market needs.

Similar to the continuous explorations of jazz musicians, the company Uber has experimented with a variety of novel ideas. In 2013 it successfully introduced Valentine's Day Uber roses, where drivers delivered roses very quickly on request (Hempel, 2013). Some of these experiments failed, such as Texas BBQ delivery in Austin where the sandwiches were spoiled before they could be delivered (ibid). Nevertheless, such experimentation is vital in differentiating Uber against many competitors such as Lyft and adapting to changes in the market.

Practicing the ability to overcome self-consciousness as jazz musicians do on a daily basis is an important ingredient of innovation. For example Reed Hastings, a founder of Netflix, had been rejected from the Entrepreneurship module at Stanford. Instead of getting discouraged, the rejection drove and motivated him to start his own business (Stanford Graduate School of Business, 2014). Another example for implementing improvisational techniques is HBO, which provides a cable-oriented television service. HBO recently expanded beyond cable transmission and is now making television shows, such as Game of Thrones. The most recent service is HBO Now, which allows customers using Android and Amazon Fire devices to access HBO and other emerging stream services.

The ability to recognize opportunities is another parallel of musical improvisation and business innovation. GoPro has introduced the GoPro Hero+ LCD camera with a built-in touch display, in-camera video trimming, and integrated $\mathrm{Wi}-\mathrm{Fi}$ experimenting with product development that creates better value for customers. In addition GoPro acquired Kolor, a virtual reality media provider, thus entering diverse markets and improvising with new content creation 
techniques. Hence, the company moves from selling products to 'content enablement, by making video editing easier, an area yet to be explored through improvisation.

Improvisational capacities enable a business to make fast decisions, in response to market changes. One of Walmart's strategies is "to get the right few people in the room to make the best decision and get on with it”, says the CEO, Doug McMillion (Bauer, 2015) to follow reflective talk example in how routines change (Dittrich et al., 2016). When improvising, it's important that the facts of the circumstances are fully understood by the people making the decisions. "Decision-making needs to be clear; otherwise you sit in a lot of pointless meetings where people chase 'everyone’s viewpoint' (Bauer, 2015).

\section{Establishing Mentoring Systems and Role Models}

The mentoring aspect of jam sessions historically developed from a need to learn the art form through oral imitation with no written materials available (Herzig and Baker, 2014). The willingness of more experienced group members to share their expertise facilitates unique and authentic learning opportunities for younger participants. A reverse example in business is Sony's Facilitating Dynamic Communication scheme (Sony, 2015b) where young millennials share their expertise in social networking and marketing with senior executives. Nokia has implemented a "Gift Culture" scheme, where managers gift their time for frequent conversations with employees (Erickson and Gratton, 2007). Furthermore Nokia has introduced two types of mentoring; "formal mentoring processes, with clear roles and responsibilities, and less formal processes, where mentoring was integrated into everyday activities” (Erickson and Gratton, 2007). It turned out that the less formal conversations were much more productive similar to findings on effective jam session gatherings where "rules are highly flexible" and open for revision depending on the circumstances of any particular jam session, but overall help maintain a degree of stability (Nelson, 1995). Every new employee at Nokia is immediately matched with "experienced peers" prepared to answer their questions as well as understanding the company culture and business processes as a whole.

Barry Clothman became a mentor to Reed Hastings who expressed "that is the kind of leader I want to be” and in turn created a similar culture of creativity and innovation in his environment (Stanford Graduate School of Business, 2014). Another example is Nikolas Tesla who became a role model for Elon Musk, CEO of Tesla. Nikolas had futuristic ideas that made his environment believe he was crazy (Tempest, 2012), which led to the downfall of his career at the end of his life. However, he was deeply committed to his ideal of improving the community's future through his ideas and never stopped working on innovation thus becoming a role model for perseverance despite obstacles.

Richard Plepler, CEO of HBO, created a Business Development Council as a mentoring opportunity within HBO. Michael Lombardo explains the impact of Plepler "doing things in a very HBO way" working together with all staff and developing a communal environment (Fuchs, 2015). As a result, each employee reaches their full potential and in return the company benefits from cross collaboration and development allowing peer learning and knowledge exchange.

CEO of Amazon, Jeff Bezos asked his employees, usually junior managers, to 'shadow' him, and asked them to comment on any idea that Bezos had in terms of whether they believed it would work or not. Having spent 3 months following a CEO who acted as a role model, one of the employees said that this experience was very rewarding and intrinsically fascinating (Nisen, 2013). This program has become an effective way for transmitting leadership throughout the 
company. Bezos’ idea was to install a leadership mentality throughout Amazon believing that even junior managers can make valuable contributions in CEO meetings (Kantor and Streitfeld, 2015). This mentoring program was known as one of the most intensive in the tech sector.

\section{Democracy and Collaboration}

Democracy and collaboration are vital for the jam session model; the quality of the product depends directly on each individual's ability to contribute equally and trade off leadership. A high level of shared mental models similar to the intent focus on performing with a shared time feel and format has been shown to foster team creativity and improve performance and satisfaction (Santos, Uitdewilligen \& Passos, 2015). Similarly, this ability is fundamental in the success and innovative growth of companies. An example of democracy within organization could be the "First Flight program" (Sony, 2015b; Hirai, 2015) where workers and external partners are encouraged to collaborate and share concepts and possibly develop a business plans. Successfully developed concepts range from e-papers to adaptive remote controls.

Another example of democracy and collaboration is the employment concept of Uber which unlike usual taxi companies does not directly employ drivers or licenses them but rather collaborates with them as independent contractors thus removing various barriers of entry (Huizinga, 2014). Strategic collaborations with partners such as Google, Baidu and Airtel improve the quality and capabilities of services combined with the app that tells drivers where to find customers matches best price with location, and facilitates easy payment. Therefore, technology and human collaboration facilitate an efficient service (Hii, 2015).

Large businesses with rigid management structure may encounter barriers in implementing a culture of democracy and collaboration. For example, even though Amazon encourages contributions of ideas by all employees the CEO Jeff Bezos admits he relies on senior management for decision-making (Cook, 2014).

\section{Leaders and Side(wo)men}

The concept of Leaders and Side(wo)men as the fifth factor of group innovation, is particularly significant when examining the process of introducing new ideas to the market. The factor is defined within the model as 'the identity of a group or company as a leader in their field, or rather as a supporter/supplier, according to their strength’ (Herzig and Baker, 2014). In jam sessions, a leader reserves the space, invites the musicians and audiences, supervises the repertoire and overall is instrumental in "inspiring the group to improve performance" (Needle, 2010). Reed Hastings (Netflix) states he does not micro manage people, and instead builds a set of great thinkers and lets them work autonomously, building an intense culture of freedom and responsibility (Stenovic, 2015) and making workers bear a side(wo)men's duties as in a jam session model. Hastings states that he prides himself "on making as few decisions as possible" (Stanford Graduate School of Business, 2014), leaving it to others, instead supporting and employing the "side(wo)men" who understand and support the business culture at Netflix and participate in decision-making.

Uber Entrepreneurs Travis Kalanick and Garrett Camp challenged a “medallion system” in cities by disrupting common fare structures and eliminating criminal background checks (Hill, 2015) thus reducing competition in the transportation market. In fact, they argue that to be an information sharing technology leading the transportation market. Recently Uber rolled out a 
new scheme called 'UberMentor' where any participant can ride for 15 minutes in an Uber car with an expert in business and/or an entrepreneur with the intention of getting excellent career advice and the opportunity to pitch ideas (Hempel, 2013; Hill, 2015) when a passenger or a driver allow a sidemen-expert to advise them.

\section{Community Support}

The environment of a jam session can be perceived in concentric circles with the musicians in the middle surrounded by the audience, the space, the sound system, the location, the media support and any community factors that influence the outcome. Similarly, a business operates in a space dependent on workers/ suppliers, competitors and of course consumers, known as external environment influencing the product in various ways. An example for cultivating such community support was the creation of Singapore Sony University (Sony, 2015a), a resource to Sony employees who can visit the Singapore campus and learn new business techniques from local businesses and academics. Furthermore, workers get community support through the Most Valuable Professional (MVP) Awards rewards for solving an advanced technical problems and 'Distinguished Engineer' systems (Sony, 2015b) recognizing contributions to key management strategies. Both awards encourage workers to be active and motivated in a community dedicated to value creation.

Community support is exemplified through collaboration with external partners such as universities and suppliers at Nokia. "We see R\&D cooperation with universities as an important component of our business and renewal strategy, driving long-term sustainability and success of our business" (Nokia report, 2005). Similarly, Uber has announced a strategic partnership with Carnegie Mellon University's robotic research unit as part of Uber's collaborators community to support business in their development of driverless cars (Hill, 2015). Collaboration within the supply chain enabled market expansion for Uber when Chinese search engine Baidu connected the search engine's map and mobile search features to Uber's app (Shu, 2014). Similar to the customer expansion by integrating Google maps into the Uber app, the company expanded their user base through the Baidu maps distribution channels. Airtel India collaborates with Uber in India as customers can pay for their trips using Airtel mobile wallet service, whilst enjoying free high speed internet access on the move (Hill, 2015). Both examples illustrate the expansion of Uber by building community support. Another example of cultivating community support is business collaborations with famous competitions and celebrities e.g. the National Hockey League collaborates with GoPro wearable cameras and enables audiences to see games from the perspective of players and referees (The Guardian, 2015). Similarly, the Rolling Stones deployed GoPro products on stage and US police forces and military incorporate the cameras into training exercises (Guardian, 2015). A vertical example of community support is a \$ 440 Million loan from the US government to Tesla Motors towards the development of environmentally friendly cars.

\section{Continuous Evaluation Systems}

Visual and verbal cues continually guide the jam session process as participants present their ideas to performers and audiences (Herzig and Baker, 2014). Continuous evaluation is embedded in the DNA of jam session and any business activity, allowing musicians and companies to monitor markets in order to refine products and processes, rather than relying on 
industry-standard procedures primarily designed to reduce costs rather than innovate. Companies benefit from strong internal evaluation procedures such as the Adobe internal evaluation system called 'Check In'. This system replaced the old 'management review' process with an instantaneous feedback option (instead of yearly). As a result, voluntary attrition was reduced by 2\% globally whilst involuntary attrition had reduced by $2.5 \%$ (Estis, 2013).

Similar to jazz musicians who through frequent participation in these sessions "pay their dues”, learn from mistakes, find the right personality match and acceptance by their peers, companies also adjust their products and services such as Sony's new customer support application through an online quality hotline which customers are keen to use. Results include process improvement and cost reduction. Another telecom company Nokia, who started as a rubber manufacturer in 1865 has continuously changed and innovated over a number of different sectors such as cables, paper products, tires, rubber boots, consumer and industrial electronics, plastics, chemicals and telecommunications infrastructure remain agile and looking at the market, available resources moving strategically its business across sectors.

IT competences aligned with strategic vision of business enabled creation of the Weblab system (Smart Insights, 2015) that does upwards of 2,000 experiments per year making it easier for customers to find information and provide e-feedback. The evaluation takes place on a very large scale with customer reviews and feedback (Lashinsky, 2012), and also includes a system in which the products can be rated and benchmarked. Continuous evaluation through the use of big data and business analytics enabled HBO to implement new types of programming outside of its existing 30- and 60-minute format” (Fuchs, 2015). In addition to variable length formats, HBO also enabled experimentation by fewer commitments to a whole series rather than individual shows. If there are issues with a show the network can just take it down, rather than being bound to a season commitment (LaPorte, 2015) As a result of faster response time, HBO was able to increase revenues. CEO Richard Plepler explained that "the key is to not be right at the beginning of the meeting but make sure they are right at the end of the meeting, that's what you want to try to foster” (Buzzfeed, 2015).

Amazon uses an innovative tool called 'Anytime Feedback Tool' for employees and managers. Every year, Amazon ranks employees according to job performance and those at the bottom are dismissed, as a process of feedback analysis. However, many employees believe that this tool leads to higher productivity in the workplace.. As a result this evaluation tool may be effective but also may lead to undeserved dismissal (Kantor and Streitfeld, 2015).

\section{DISCUSSION}

The Jam Session Model for Group Creativity and Innovative technology assesses the different factors in regards to their relevance to group innovation and applications to entrepreneurship and creative communities. Beyond establishing and exemplifying the model factors, it also becomes clear through this analysis that the factors overlap and vary in importance. Based on the cases discussed, we argue that the factors of Improvisation, Knowledge of the Field as well as Establishing Mentoring Systems are of the highest importance to the model. Knowledge of the Field is a crucial component at every level of an organization striving for the highest level of human capabilities, skills and creativity. Establishing Mentoring Systems works as a complement to other factors, such as Continuous Evaluation Systems and growing junior Leaders and Side(wo)men. Knowledge is essential when it comes to establishing a creative community and an entrepreneurial unit within an organization. The combination of having the 
most knowledgeable and skilled workers with the relevant competencies (LEAD, 2014) in an environment that nurtures improvisation and continued evaluation creates an incubator for innovative technology

For instance, HBO exemplifies an improvisational approach to programming. Michael Lombardo affirms that improvisation and adaptability are core aspects of his job (Fuchs, 2015). He posits "my decisions consist of risks that could either have really positive or negative effects", similar to the quick decisions that jazz players make at every moment. Those decisions are strengthened by competencies gained through years of practice and participation in jam session and group performances. For example, with the decision to give John Oliver, a British comedian, his own news program during a prime Sunday night slot on TV; "the network was placing a big, high-risk bet on the comedian” (Fuchs, 2015). We found that many of the solutions at Nokia, Uber, Netflix, Sony, HBO, and Amazon that were implemented in response to challenges were the result of a group culture that nurtured the most prominent factors of the jam session model: Improvisation, Knowledge of the Field, and Establishing Mentoring Systems.

Democracy and Collaboration are essential for group innovation. An environment where every group member is able to confidently share ideas and trade leadership has been found conducive to creativity (Audretsch and Belitski, 2013). With a democratic process in place, the amount of ideas can be optimized and the best options explored. Expanding the conversation between advisors, writers, producers, directors and casts for such companies as Netflix and HBO is comparable to the factor of Community Support for a successful jam session. The key lesson is to provide the best community and culture to drive innovation forward (LaPorte, 2015).

We emphasize that "transparency and openness" coupled with a conducive community support environment "where the senior team is listening all the time” (Buzzfeed, 2015) is crucial for enabling organizational improvisation. By allowing employees to raise concerns and articulate ideas to their co-workers, potential ideas and opportunities are captured.

Continuous Evaluation throughout the improvisation process becomes the essence of innovation throughout the product life cycle. For example, a quick reaction after a serious accident swiftly introduced a titanium underbody shield to the existing protection on all new Tesla cars, with free upgrade available on existing ones (Dyer et al., 2015). Similarly, after learning about the back seats problem in the Tesla model S, service workers changed seats in a matter of weeks. Especially in the media world, the pace of Continuous Evaluation has increased in response to the quickly changing landscape and the arrival of Netflix and Hulu.

The principle of Democracy and Collaboration in an organization facilitates the option for all employees to become leaders and contribute ideas spilling over knowledge and easing the exchange of it (Audretsch and Belitski, 2015). A good demonstration of this is when Buchmueller, a junior engineer at Amazon, suggested the 'delivery-by-drone' project (Kantor and Streitfeld, 2015). Successful leadership means facilitating a continuous exchange of ideas in a musical as well as organizational context between all participants not inhibited by rank or seniority (Baker and Herzig, 2014).

Even though the relevance of the seven secrets of organizational innovation may vary between industries, company size, level of team maturity and firm age, all factors have been exemplified in leading innovative units and the model provides a tool box for the innovative process. As such it can be employed for analysis of a company's or organization's creative culture and provides a basis for strategic planning, consultation, and entrepreneurship pedagogy.

\section{Conclusions and Implications for Research and Practice}


This study contributes to research on innovative technology in four important ways. First, we build on the jam session model for group creativity to exemplify its potential for facilitating organizational innovation through effective training of improvisation and risk-taking (Zack, 2000; Barrett, 1998, 2012; Vera and Crossan, 2005) Second, we introduce a concept of organizational innovation rooted in the jazz jam session experience and implement the seven factor jam session model as an effective tool box to document innovative capacities such as expertise, community support, evaluation systems, leadership and sideman, democratic and collaborative culture, mentoring systems. The successful implementation can increase a business' appeal to shareholders (e.g. suppliers, partners, consumers, government, non-for-profit) similar to jam session gatherings who have more appeal to community and audiences (Meyer et al., 1998) if all factors are cultivated to their highest level.

Third, this study documents each factor of the jam session model with evidence from eight case studies of companies that have been identified as innovative leaders (Forbes, 2015) of various size, background, and collaborative models. We also provide evidence suggesting that improvisation and creativity can be learned through continued practice (Vera and Crossan 2005) and refined through continuous evaluation systems as well as mentorship support and trading leadership (Herzig and Baker, 2014). Our results shed light on the opportunities provided by the jam session model as a tool box for group creativity going beyond improvisational theatre (Vera and Crossan, 2005) and music literature (Zack, 2000; Barrett, 2012; Herzig and Baker, 2014).

Finally, we offer a model for innovation in teams building on prior research in organization science (Mayer et al., 1998) and creativity and innovation management literature (Aagaard and Gertsen, 2011; Santos, Uitdewilligen and Passos, 2015; Frishammar et al., 2016) , Dahlskog, Krumlinde and Yazgan, 2016). We emphasize that each factor provides a different array of benefits to team creativity, however the effective combination of the factors and interaction among them provides the key for innovativeness and creative decision-making. Thus, the model can be applied in business and scientific communities alike as a tool to identify effective practices as well as cultivate risk-taking abilities needed to generate new solutions and ideas.

Further research may focus on implementation options of the model in an innovative organization, such as the effects of engaging regularly in conscious improvisation activities, various competency levels, democratic team efforts, types and frequency of mentorship opportunities, community engagement, and distribution of specific roles. An in-depth analysis of the actions of a jazz combo and parallel theories of creativity are available in Herzig and Baker, 2014, as the initial model factors were developed. Overall, the factors may be immediately applied in an organization as a framework for establishing an entrepreneurial culture.

Following calls for more empirical evidence (Frishammar et al., 2016) we recommend that future research may focus on providing empirical evidence and a quantitative test on the impact of each factor of the jam session model on radical and incremental innovation in organizations as well as product and process innovation. Similar to the empirical test of improvisation and innovative performance in teams (Vera and Crossan, 2005) quantitative analysis of each of the seven factors will provide further insights on the relevance and the size of impact of each factor, as well as prove which factors of the jam session model may act as an efficient compliments. Using firm-level data and innovation characteristics, the model has significant potential for enriching organization science literature. 


\section{REFERENCES}

Aagaard, A., Gertsen, F. (2011). Supporting radical front end innovation: perceived key factors of pharmaceutical innovation. Creativity and Innovation Management, 20(4), 330-346.

Audretsch, D. B., Hayter, C. S., \& Link, A. N. (Eds.). (2015). Concise guide to entrepreneurship, technology and innovation. Edward Elgar Publishing.

Audretsch, D., Belitski, M. (2013). The missing pillar: the creativity theory of knowledge spillover entrepreneurship. Small Business Economics 41(4): 819-836.

Audretsch, D., Belitski, M. (2015). Creativity Spillover of Entrepreneurship Theory: Evidence from European Cities, in Karlsson, C., Gråsjö, U., \& Wixe, S. (Eds.) Innovation and Entrepreneurship in the Global Economy: Knowledge, Technology and Internationalization. Edward Elgar Publishing.

Barrett, F. (1998). Creativity and improvisation in jazz and organisations: implications for organisational learning. Organization Science, 9(5), 5.

Barrett, F. (2012). Yes to the mess: Surprising leadership lessons from jazz. Harvard Business Review Press.

Bastien, D., Hostager T.J,(1988). Jazz as a process of organizational innovation. Communication Research, 15(5): 582-602.

Bauer, T. (2015). A lesson about decision-making from Walmart. Ted Bauer's blog about leadership, Texas. http://thecontextofthings.com/2015/03/25/decision-making-and-walmart/

Becker, H. (2000). The etiquette of improvisation. Mind, Culture, and Activity 7: 171-200.

Berliner, P. F. (2009). Thinking in jazz: The infinite art of improvisation. University of Chicago Press.

Buzzfeed (2015). BuzzFeed Brews talks to HBO CEO Richard Plepler. http://www.cbsnews.com/videos/buzzfeedbrews-talks-to-hbo-ceo-richard-plepler/

Cameron, w. (1956). Sociological notes on the jam session. The Second Line 7(11-12): 6-10.

Carr, I., Fairweather, D., Priestley, B. (1987). Jazz: the essential companion. Prentice-Hall.

Cohen, B. (2005). Sustainable Valley Entrepreneurial Ecosystems. Business Strategy and the Environment, 15, 114.

Cook, J. (2014). Shareholder letter: Amazon's Jeff Bezos on innovation, urban campuses and Mayday marriage proposals. http://www.geekwire.com/2014/shareholder

Cunha, J. and Cunha, M.P. (2008). Improvisation in Organizations. In Barry, D. and Hansen, H. (Eds.), The Sage Handbook of New Approaches in Management and Organization. Sage, Thousand Oaks, CA, pp. 385-95.

Cunha, M.P., Cunha, J.V. and Kamoche, K. (1999). Organizational Improvisation: What, When, How and Why. International Journal of Management Reviews, 1, 299-341.

Dennis, N., Macaulay, M. (2003). Jazz and marketing planning. Journal of Strategic Marketing, 11: 177-185.

DeVeaux, S. (1997). The birth of bebop: a social and musical history. University of California Press, Berkeley.

Derousseau, R. (2015). A company in crisis is an opportunity for change. Retrieved at http://fortune.com/2015/07/10/crisis-company-culture/.

Dittrich, K., Guérard, S., \& Seidl, D. (2016). Talking about routines: The role of reflective talk in routine change. Organization Science, 27(3), 678-697.

Dyer, J., Gregersen, H., Furr, N. (2015). Decoding Tesla's Secret Formula. Retrieved at http://www.forbes.com/sites/innovatorsdna/2015/08/19/teslas-secret-formula

Dyer, J., \& Gregersen, H. (2015). How we rank the world's most innovative companies 2015.

Estis, R. (2013). Blowing up the performance review: Interview with Adobe's Donna Morris. Retrieved at http://ryanestis.com/employee-engagement/adobe-interview/.

Feinberg, M., Nemeth, C. (2008). The "Rules" of Brainstorming: An Impediment to Creativity? IRLE Working Paper No. 167-08.

Fuchs, M. (2015). Michael Fuchs Interview. Retrieved at http://www.emmytvlegends.org/interviews/people/michael-fuchs

Guardian (2015). GoPro, NHL deal will let fans watch hockey from player's point of view. Retrieved at http://www.theguardian.com/sport/2015/jan/23

Erickson, T.J., Gratton, L. (2007). Eight ways to build collaborative teams. Harvard Business Review 11: 1-11.

Frishammar J., Dahlskog, E., Krumlinde, C., Yazgan, K. (2016). The Front End of Radical Innovation: A Case Study of Idea and Concept Development at Prime Group. Creativity And Innovation Management 2: 179.

Hadida, A., Tarvainen, W., Rose, J. (2015). Organizational improvisation: a consolidating review and framework. International Journal of Management Reviews, 17: 437-459. 
Hempel, J. (2013). Video and transcript: Uber CEO Travis Kalanick. Retrieved at http://fortune.com/2013/07/23/video-and-transcript-uber-ceo-travis-kalanick/

Hirai, K. (2015). To Our Shareholders - November 2015. Investor Relations, Sony. Retrieved at http://www.sony.net/SonyInfo/IR/strategy/

Hargadon, A. B., \& Bechky, B. A. (2006). When collections of creatives become creative collectives: A field study of problem solving at work. Organization Science, 17(4), 484-500.

Hatch, M.J. (1998). Jazz as a metaphor for organizing in the 21st Century. Organization Science, 9(5): 556-568.

Hatch MJ, Weick KE (1998) Critics' Corner-Critical Resistance to the Jazz Metaphor. Organ. Sci. 9(5): 600-604.

Heilmann, P. (2007). High Level Competence: A Tool For Coping With Organizational Change. Journal of European Industrial Training, 31(9): 727 - 741.

Herzig, M. (2011). David Baker: a legacy in music. Indiana University Press.

Herzig, M., Baker, D. (2014). Beyond Jamming: A Historical and Analytical Perspective on the Creative Process. Journal of the Music \& Entertainment Industry Educators Association, 14.

Holbrook, M.B. (2008). Playing the Changes on the Jazz Metaphor. Now Publishers Inc.

Hmieleski, K.M., Corbett, A.C. (2008). The contrasting interaction effects of improvisational behavior with entrepreneurial self-efficacy on new venture performance and entrepreneur work satisfaction. Journal of Business Venturing 23(4), 482-496.

Huizinga, D. (2014). Uber is changing the landscape of Transportation. Retrieved at http://opportunitylives.com/uber-is-changing-the-landscape-of-transportation/

Kao, J. (1996). Jamming - the art and discipline of business creativity. HarperCollins.

Klapper, L., Amit, R. H., Guillen, M. F. and Quesada, J. M. (2007) Entrepreneurship and Firm Formation Across Countries. World Bank Policy Research Working Paper No. 4313.

Laporte, N. (2015). HBO To Netflix: Bring It On. Retrieved at http://www.fastcompany.com/3044284/bring-it-on

Lewin, A.Y. (1998). Introduction-Jazz Improvisation as a Metaphor for Organization Theory. Organization Science, 9(5):539-539.

LEAD (2014). E-Leadership Skills for Small and Medium Sized Enterprises project. (European Commission, Directorate-General for Enterprise and Industry, Brussels).

Hill, S. (2015). How Stephen Colbert Blew It with Uber CEO Travis Kalanick. Retrieved at http://www.huffingtonpost.com/steven-hill/how-stephen-colbert-blew-_b_8128292.html

Kantor, J., \& Streitfeld, D. (2015). Inside Amazon: Wrestling big ideas in a bruising workplace. New York Times, $15,74-80$.

Lashinsky, A. (2012). Amazon’s Jeff Bezos: The Ultimate Disrupter. Retrieved September, 3, 2013.

Limb, C., Braun, A. (2008). Neural Substrates of Spontaneous Musical Performance: An fMRI Study of Jazz Improvisation. PLoS ONE 3(2): e1679.

Meyer, A., Frost, P., Weick, K. (1998). The Organization Science Jazz Festival: Improvisation as a Metaphor for Organizing-Overture. Organization Science, 9(5):540-542.

Moorman, C., Miner, A.S. (1998). Organizational Improvisation and Organizational Memoir. The Academy of Management Review 23(4): 698-723.

Needle, D. (2010). Business in context: an introduction to business and its environment. 5th ed. South-Western Cengage Learning.

Nelson, L. (1995). The social construction of the jam session. Jazz Research Papers 15: 95-100.

Nisen, M. (2013). Jeff Bezos runs the most intense Mentorship program in tech. Retrieved at http://www.businessinsider.com/jeff-bezos-technical-advisors-2013-10

Obstfeld, N. (2012). Creative Projects: A Less Routine Approach Toward Getting New Things Done. Organization Science, 23(6):1571-1592.

Perry-Smith, J.E., Shalley, C.E. (2014). A social composition view of team creativity: The role of member nationality-heterogeneous ties outside of the team. Organization Science, 25(5): 1434-1452.

Peplowski, K. (1998). The Process of Improvisation. Organization Science, 9(5): 560-561.

Sawyer, K. (1992). Improvisational creativity: an analysis of jazz performance. Creativity Research Journal, 5, pp. 253-263.

Sawyer, K. (2006). Group creativity: musical performance and collaboration. Psychology of Music 34(2): 148-165.

Serrat, O. (2009). Harnessing creativity and innovation in the workplace. Retrieved at https://www.adb.org/sites/default/files/publication/27596/harnessing-creativity-and-innovationworkplace.pdf 
Shu, C. (2014). Chinese Search Engine Baidu Confirms Strategic Investment in Uber, Will Aid Ride Requests. Retrieved at http://techcrunch.com/2014/12/16/baiduber-is-a-do/

Santos, C. M., Uitdewilligen, S., \& Passos, A. M. (2015). Why is Your Team More Creative Than Mine? The Influence of Shared Mental Models on Intra-group Conflict, Team Creativity and Effectiveness. Creativity and Innovation Management, 24(4), 645-658.

Sony (2015a). Nurturing and leveraging engineering talent. CSR Report Retrieved at http://www.sony.net/SonyInfo/csr_report/employees/training/index5.html

Sony (2015b). Sony Further Accelerates its New Business Creation Efforts: Launches the "First Flight" Platform for Crowdfunding and E-Commerce. Retrieved at http://www.sony.net/SonyInfo/News/Press/201507/15-061E/

Stenovic, T. (2015). One Reason For Netflix's Success - It Treats Employees Like Grownups. Huffpost Tech Retrieved at http://www.huffingtonpost.com/2015/02/27/netflix-culture-deck-success_n_6763716.html

Tempest, M. (2012). The electric rise and fall of Nikola Tesla. TED Talks. Retrieved at ,https://www.ted.com/talks/

Tsoukas, H. (2009). A dialogical approach to the creation of new knowledge in organizations. Organization Science, 20(6): 941-957.

Vera, D., Crossan, M. (2005). Improvisation and innovative performance in teams. Organization Science, 16(3): 203-224.

Walmart (2015). Walmart Responsible Sourcing Partnerships. Report Retrieved at http://corporate.walmart.com/sourcing/collaboration.

Weick, K. (1990). Managing as improvisation: Lessons from the world of jazz. Aubrey Fisher Memorial Lecture, University of Utah.

Wessner, Charles W. (2005). Entrepreneurship and the Innovation Ecosystem: Policy Lessons from the United States. in Local Heroes in the Global Village: Globalization and New Entrepreneurship Policies. D. B. Audretsch, H. Grimm, and C. W. Wessner (Eds). Springer.

Yoo, Y., Boland, R.J., Lyytinen, K., Majchrzak, A. (2012). Organizing for innovation in the digitized world. Organization Science, 23(5): 1398-1408.

Zack, M.H. (2000). Jazz improvisation and organizing: Once more from the top. Organization Science, 11(2): 227234. 